7. Протокол № 19-121-85/1160810/ государственных приемочных испытаний машины для уборки лука-репки и севка ЛКП-1,8. Поволжская МИС, Кинель, 1985.

8. Рейнгарт Э.С., Мейлахс И.И., Раскатов В.Г., Сигал И.Я. Машина ЛКП-1,8 повышенной производительности для уборки лука // Тракторы и сельхозмашины. - 1986. - № 8. - С. 44-45.

9. Хвостов В.А., Рейнгард Э.С. Машины для уборки корнеплодов и лука (теория, конструкция, расчет). M., 1995. - 391 c.

10. Better onions with direct harvesting. - Arable Farming, 1977, Vol. 4, No. 7, p. 25.

11. Introduction of onion harvester. // Farming mechanization, 1975, No. 5, S. 34.

12. Kampen J. Beitrage der Forschung zur Losung technischen und wirtschaftlicher Probleme des Freilandgemusebaues in den Niederlanden. - Gemuse, 1976, Bd. 12, H. 4, S. 142-144.

13. Systematization of onion harvesting work by farmers. Farming Mechanization, 1976, No. 1, p. 25-30. (Japan).

14. Schoneveld J., Meeldijk B. Mechanisatie van de groenteelt in de verenigde Staten van America. - Landbouwmechanisatie, 1976, j. 27, N 4, S. 344-350.

15. SchoneveldJ. Mogelijkheden en knelpunten in mechanische oogst. - Grochten Fruit, 1978, j. 33, N 45, S. 58-59.

16. Tomita M., Kawasaki K., Honjo H., Kanetani J. Studies on the mechanical harvest system for onions. -
R. Bull. Hokaido Nat. Agr. Exper. Stat, 1978, No. 122, S. $55-58$.

17. Unter Zwiebeln 51 ha. - Chemie und Technik in der Landwirtschaft, 1979, H. 8, S. 276-277.

18. Viscardi K. Nie tylko wyposazenie techniczne decydiye o sukeesie mechanizugi procesu produkcji warryw polowych. - Masz. Ciagn. Roin, 1978, z. 25, No. 4, S. 21-25.

19. Volks B., Banhoizer G. Rationelle Organisation der Production und Ernte von Speisezwiebeln bei einer hohen konner Vulde Gross Bornecke. - Gartenbau, 1976, Bd. 23, H. 8, C. 232-233.

20. Zoldi J. A voroshagjmatermeles nomplex gepesitese, Budapest, 1977, S. 1-31.

Протасов Андрей Анатольевич, $\partial-p$ техн. наук, проф. кафедры «Процессы и сельскохозяйственные машины в АПК», Саратовский государственный аграрный университет имени Н.И. Вавилова. Россия.

Макаров Сергей Анатольевич, канд. техн. наук, доцент кафедры «Механика и инженерная графика», Саратовский государственный аграрный университет имени Н.И. Вавилова. Россия.

410056, г. Саратов, ул. Советская, 60.

Тел.: (8452) 74-96-59.

Ключевые слова: двухфазная технология; средства механизации; уборка; лук-репка; универсальные машины.

\title{
TECHNOLOGY AND MEANS OF MECHANIZATION FOR TWO-PHASE HARVESTING OF SEED ONION AND UNIVERSAL HARVESTING MACHINES
}

Protasov Andrey Anatolyevich, Doctor of Technical Sciences, Professor of the chair "Processes and Agricultural Machines in AIC", Saratov State Agrarian University named after N.I. Vavilov. Russia.

Makarov Sergey Anatolyevich, Candidate of Technical Sciences, Associate Professor of the chair "Mechanics and Engineering Graphics", Saratov State Agrarian University named after N.I. Vavilov. Russia.

Keywords: two-phase technology; mechanization; harvesting; seed onion; universal machines.

The single-phase and two-phase methods of bulb onion harvesting is briefly described comparison in terms of their optimal application depending on the variety, weather conditions and technical equipment of agricultural producers. The possibilities of post-harvest refinement in the final product and their impact on the cost. The technologies and means of mechanization for two-phase cleaning, their advantages and disadvantages are analyzed. Based on the analysis of the use of harvesting machines and the possibility of their operations, a classification of two-phase bulb onion harvesting technologies was developed. Considered universal means of mechanization and harvesting machines transformers allow using combines intended for other crops (potatoes, carrots, etc.) in the harvesting of bulb onion.

\section{ТАРИРОВОЧНАЯ ЗАВИСИМОСТЬ ПРИ УЛЬТРАЗВУКОВОМ КОНТРОЛЕ КОЭФФИЦИЕНТА ФИЛЬТРАЦИИ БЕТОНА}

\author{
СЕМЕНЕНКО Сергей Яковлевич, Федеральный научный центр агроэкологии, комплексных \\ мелиоращий и защитного лесоразведения Российской академии наук
}

\section{МАРЧЕНко Сергей Сергеевич, Федеральный научный центр агроэкологии, комплексных} мелиоращий и защитного лесоразведения Российской академии наук

\begin{abstract}
АРЬКОВ Дмитрий Петрович, Федеральный научный центр агроэкологии, комплексных мелиораций и защитного лесоразведения Российской академии наук
\end{abstract}

В работе обосновывается развитие новых методов определения коэффициента фильтрации как одного из факторов, влияющих на безопасную работу гидротехнических сооружений, диагностирование которого способствует принятию своевременных решений по ремонту, продлевая этим срок службы сооружений, сокращая затраты на эксплуатацию. Приводятся принципы построения тарировочной зависимости при контроле коэффициента фильтрации бетонных облицовок, параметры оценки построенных зависимостей.

Введение. Основными факторами, влияющими на безопасность и долговечность бетонных и железобетонных конструкций гидротехнических сооружений, являются воздействия воды, водяного пара, льда, отрицательных температур $[1,2]$. К материалам конструкций, работающим в подоб- 
ных условиях, стандартами по проектированию предъявляется требование по плотности, которое характеризуется маркой по водонепроницаемости.

Воздействие агрессивных факторов ухудшает начальные, принятые по проекту характеристики материалов конструкций, которые по истечении определенного срока эксплуатации начинают не соответствовать необходимым значениям. В связи с этим при диагностировании технического состояния построенных ранее водохозяйственных объектов возникает острая необходимость определения параметров водонепроницаемости бетона (коэффициент фильтрации, марка бетона по водонепроницаемости), не выводя на долгое время из эксплуатации мелиоративные сооружения [9].

Оперативный контроль коэффициента фильтрации бетона мелиоративных и гидротехнических сооружений будет способствовать принятию своевременных решений по ремонту и реконструкции, тем самым обеспечивая безопасность сооружений, повышая срок службы и сокращая затраты на эксплуатацию [5].

Цель исследования - построение тарировочной зависимости для применения неразрушающего метода определения марки бетона по водонепроницаемости на основании результатов ультразвуковой диагностики гидротехнических сооружений мелиоративного назначения методом поверхностного прозвучивания с отбором контрольных образцов-кернов.

Методика исследований. В настоящее время на практике применяют следующие стандартные методы контроля водонепроницаемости бетона, которые можно разделить на следующие группы.

1. Прямые, направленные на моделирование механизма переноса воды. Оценка водонепроницаемости заключается в определении количества времени, при котором бетонная поверхность способна противостоять воздействию воды с фиксацией момента проникновения жидкости в тело бетона с расчетом объема воды поглощенной бетоном. К этой группе можно отнести и стационарные лабораторные установки, принцип которых основан на определении количества времени, при котором бетонная поверхность способна противостоять воздействию воды, фиксации начала фильтрации по «мокрому пятну», и объема воды поглощенной бетоном. При этом способе погрешность измерения незначительна, но применение его в реальных условиях для оперативного контроля сооружений большой протяженности связано с большими трудовременными затратами [10].

2. Косвенные. Определение водонепроницаемости выполняется по измерению объема проходящего через бетон воздуха. Данные методы основаны на использовании приборов, создающих разряжение на поверхности бетона с последующим контролем потери вакуума, характеризующего воздухопроницаемость бетона.

Сотрудниками ПНИИЭМТ - филиала ФГБНУ «Федеральный научный центр агроэкологии, комплексных мелиораций и защитного лесоразведения РАН» предложен новый эффективный ультразвуковой метод оценки коэффициента фильтрации бетонных конструкций мелиоративных сооружений, основанный на использовании эмпирических зависимостей, полученных при ультразвуковом исследовании конструкций [6, 7].

Для установления зависимости скорости прохождения ультразвуковых колебаний и коэффициента фильтрации за единичное значение (результат) принимали среднее значение скорости распространения ультразвука в серии и коэффициент фильтрации, определенный одним из стандартных методов [3, 4].

Определение скорости прохождения ультразвуковых колебаний в образцах.

Измерение скорости прохождения ультразвуковых колебаний выполняли ультразвуковым дефектоскопом Пульсар 1.2, прозвучивание образцов производили поверхностным способом на нижней (при формовании) грани образца (рис. 1).

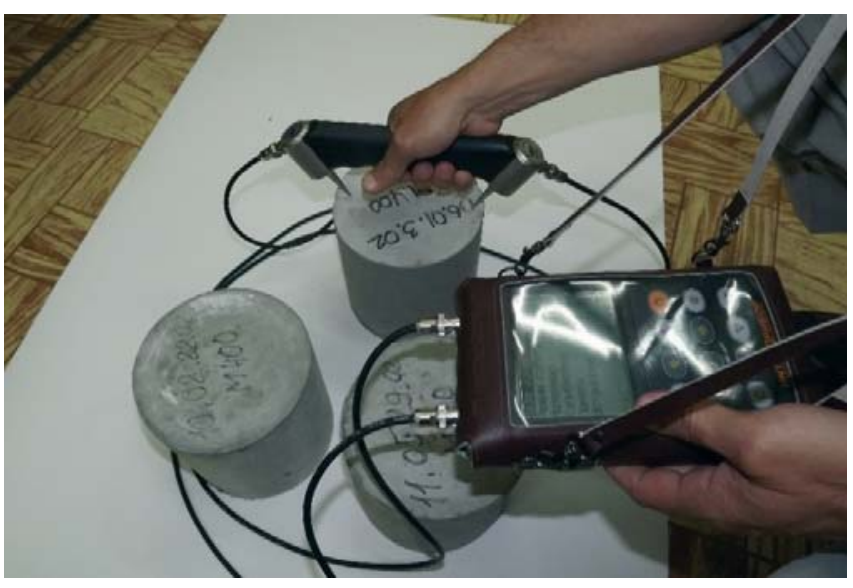

Рис. 1. Измерение скорости распространения ультразвука в образиах

При измерении визуально контролировали зону контакта ультразвуковых преобразователей споверхностью бетона, в которой не должно быть раковин и воздушных пор глубиной более 3 мм и диаметром более 6 мм, а также выступов более 0,5 мм. Поверхность бетона предварительно очищали от пыли [8].

Определение коэффициента фильтрации.

Для определения коэффициента фильтрации образцов использовали фильтратометр ФМ 3 (в соответствии с ГОСТ 12730.5-84).

Фильтрационный коэффициент бетона $K_{\phi}$, см/с, определяли по формуле:

$$
K_{\phi}=\left(\frac{m \delta^{2}}{240 \tau \rho}\right)^{1,31},
$$

где $\delta$ - путь фильтрации, равный $\mathrm{D} / 2, \mathrm{~cm} ; \tau$ - время испытания образцов, с; $\rho$ - избыточное давление в фильтратометре, МПа; $m$ - коэффициент водопоглощения, $\mathrm{H} / \mathrm{cm}^{3}$.

Коэффициент водопоглощения m определяли по формуле

$$
m=\frac{Q}{1,08 V},
$$


где $Q$ - вес воды, поглощенной бетоном, H; $V$ объем бетона, насыщенного водой, см$^{3}$.

Объем бетона V, насыщенного водой, рассчитывали по формуле

$$
V=\frac{\pi D^{3}}{12}
$$

Среднее значение фильтрационного коэффициента $K_{\phi}$ образцов рассчитывали по данным серии опытов, проведенных в соответствии с требованиями п. 3.4.4 ГОСТ 12730.5-84. Результаты испытаний трех серий образцов приведены в табл. 1 .

На скорость распространения ультразвука в бетоне могут влиять различные факторы, поэтому для использования предложенного ультразвукового контроля необходимо предварительно построить тарировочную связь между скоростью распространения ультразвука и коэффициентом фильтрации с испытанием контрольных образцов, отобранных из эксплуатируемых сооружений.

Основные требования к изготовлению и испытанию тарировочных образцов (цилиндров) должны соответствовать ГОСТ 12730.5-84, но при этом необходимо выполнить ряд специальных требований:

образцы отбираются из конструкций, работающих в аналогичных условиях;

наименьший размер образца а должен быть больше удвоенной длины волны используемых ультразвуковых колебаний, т.е. $a>2$;

опытные образцы - кубы должны быть размером не менее $20 \times 20 \times 20$ см, цилиндры - диаметром не менее 15 см;

погрешность в определении размеров и веса образца не должна превышать 0,2 \%.
Результаты исследований. Для подтверждения предложенных утверждений и верификации ультразвукового метода диагностики коэффициента фильтрации, оценки возможной погрешности измерений, на примере обследования образцов разных марок по водонепроницаемости построены графики, характеризующие зависимость скорости ультразвука и коэффициента фильтрации. Общий график, приведенный на рис. 2, описан функцией второго порядка:

$$
K_{\phi}=2 \mathrm{E}-16 V^{2}-2 \mathrm{E}-12 \mathrm{~V}+4 \mathrm{E}-09,
$$

где $K_{\phi}-$ коэффициент фильтрации бетона; $V$ скорость распространения ультразвуковых колебаний; 2Е-16; 2Е-12 и 4Е-09 коэффициенты, полученные эмпирическим путем.

За единичное значение скорости ультразвука принимали среднеарифметическое значение результатов испытаний серии образцов.

Средние значения коэффициента фильтрации $K_{\phi}$ и скорости ультразвука $V, \mathrm{M} / \mathrm{c}$, определяли по следующим формулам:

$$
\begin{aligned}
& \bar{K}=\frac{\sum_{j=1}^{N} K}{N} ; \\
& \bar{V}=\frac{\sum_{j=1}^{N} V_{j}}{N},
\end{aligned}
$$

где $N$ - число участков или образцов, испытанных при установлении градуировочной зависимости; $V$ - скорость распространения ультразвука; $K_{j}$, $V_{j}$ - единичные значения коэффициента фильтрации и скорости распространения ультразвука для -го участка или серии измерений.

Эмпирические коэффициенты можно най-

\begin{tabular}{|c|c|c|c|c|c|c|c|}
\hline № образца & $\begin{array}{c}\text { Скорость } \\
\text { распростране- } \\
\text { ния УЗВ }\end{array}$ & $\begin{array}{c}\text { Время } \\
\text { распростране- } \\
\text { ния УЗВ } \\
t, \text { мсм }\end{array}$ & $\begin{array}{c}\text { Время } \\
\text { испыта- } \\
\text { ния } \tau, \text { с }\end{array}$ & $\begin{array}{c}\text { Диаметр затем- } \\
\text { ненного круга } \\
\text { (мокрого пятна) } \\
D, \text { см }\end{array}$ & $\begin{array}{c}\text { Объем бетона, } \\
\text { насыщенного } \\
\text { водой } V, \text { см}^{3}\end{array}$ & $\begin{array}{c}\text { Коэффициент } \\
\text { водопоглоще- } \\
\text { ния } m\end{array}$ & $\begin{array}{c}\text { Коэффициент } \\
\text { фильтрации } \\
\text { бетона } K_{\phi}, \text { см/с }\end{array}$ \\
\hline 07.01 .23 .08 & 4801,4 & 24,86 & 270 & 10,3 & 285,93 & 0,000187109 & $2,334 \mathrm{E}-11$ \\
\hline 07.02 .23 .08 & 4657 & 26,37 & 68 & 11,2 & 367,622 & 0,00014553 & $1,273 \mathrm{E}-10$ \\
\hline 07.03.23.08 & 4609 & 25,73 & 120 & 10,4 & 294,339 & 0,000181763 & $6,669 \mathrm{E}-11$ \\
\hline 07.04.23.08 & 4776 & 25,28 & 127 & 10,5 & 302,911 & 0,000176619 & $6,114 \mathrm{E}-11$ \\
\hline 07.05 .23 .08 & 4763 & 25,27 & 117 & 10,6 & 311,649 & 0,000171667 & $6,724 \mathrm{E}-11$ \\
\hline 07.06 .23 .08 & 4759 & 25,65 & 118 & 10,5 & 302,911 & 0,000176619 & $6,732 \mathrm{E}-11$ \\
\hline \multicolumn{7}{|c|}{ Среднее значение коэффициента фильтрации бетона } & $6,391 \mathrm{E}-11$ \\
\hline 02.01 .06 .12 & 3596 & 33,71 & 45 & 11,2 & 367,622 & 0,00014553 & $2,187 \mathrm{E}-10$ \\
\hline 02.02 .06 .12 & 3822 & 31,04 & 44 & 10,5 & 302,911 & 0,000176619 & $2,451 \mathrm{E}-10$ \\
\hline 02.03 .06 .12 & 3725 & 32,23 & 38 & 10,9 & 338,86 & 0,00015788 & $2,828 \mathrm{E}-10$ \\
\hline 02.04 .06 .12 & 3705 & 32,1 & 32 & 10,4 & 294,339 & 0,000181763 & $3,767 \mathrm{E}-10$ \\
\hline 02.05 .06 .12 & 3730 & 32,18 & 31 & 10,8 & 329,62 & 0,000162306 & $3,738 \mathrm{E}-10$ \\
\hline 02.06 .06 .12 & 3700 & 32,43 & 25 & 11,6 & 408,434 & 0,000130988 & $4,512 \mathrm{E}-10$ \\
\hline \multicolumn{7}{|c|}{ Среднее значение коэффициента фильтрации бетона } & $3,298 \mathrm{E}-10$ \\
\hline 13.01 .13 .03 & 4900 & 24,9 & 62 & 7 & 89,751 & 0,000596089 & $2,660 \mathrm{E}-10$ \\
\hline 13.02 .13 .03 & 4922 & 24,5 & 95 & 8,9 & 184,46 & 0,000290025 & $1,110 \mathrm{E}-10$ \\
\hline 13.03 .13 .03 & 4788 & 25,28 & 78 & 8,4 & 155,09 & 0,000344959 & $1,55 \mathrm{E}-10$ \\
\hline 13.04 .13 .03 & 4956 & 23,7 & 150 & 10,8 & 329,624 & 0,000162306 & $4,738 \mathrm{E}-11$ \\
\hline 13.05.13.03 & 4900 & 24,2 & 68 & 8,6 & 166,434 & 0,000321447 & $1,800 \mathrm{E}-10$ \\
\hline 13.06 .13 .03 & 4938 & 24,2 & 129 & 8,7 & 172,308 & 0,00031049 & $7,664 \mathrm{E}-11$ \\
\hline \multicolumn{7}{|c|}{ Среднее значение коэффициента фильтрации бетона } & $1,012 \mathrm{E}-10$ \\
\hline
\end{tabular}
ти графически или аналитически как параметры

Таблица 1

Сводная таблица результатов расчета $K_{\phi}$ и скорости распространения УЗВ 


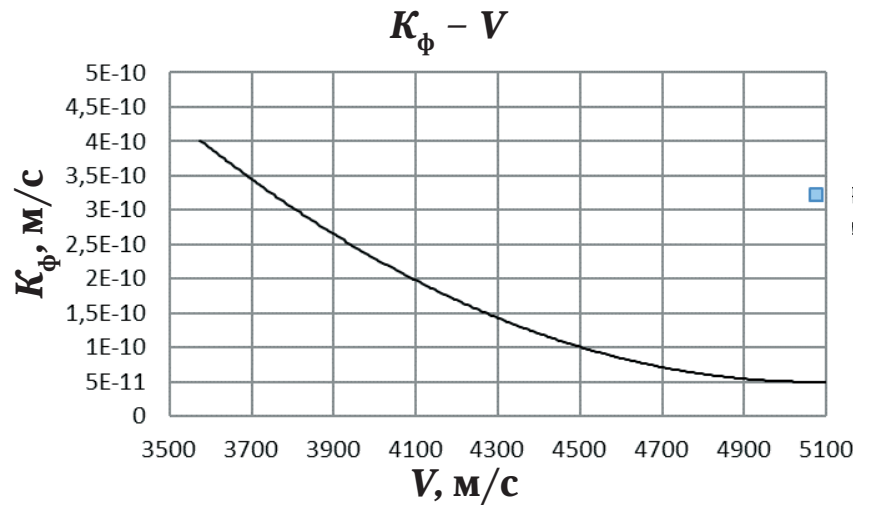

Рис. 2. График изменения скорости УЗК от коэффициента фильтрации для марок по водонепроницаемости W8, W10, W12

уравнения средней линии (линии регрессии) поля опытных точек на графике. Средняя линия проводится так, чтобы сумма квадратов отклонений опытных точек от этой линии была наименьшей.

Степень тесноты связи между скоростью ультразвука и коэффициентом фильтрации бетона, рассчитанных с использованием выражений (5) и (6), измеряется коэффициентом корреляции $\mathrm{r}$, который находят по формуле

$$
r=\frac{\sum\left(K_{\phi p}-K_{\phi p}^{\prime}\right)\left(K_{\phi K}-K_{\phi K}^{\prime}\right)}{\sqrt{\sum\left(K_{\phi p}-K_{\phi p}^{\prime}\right)^{2} \sum\left(K_{\phi p}-K_{\phi p}^{\prime}\right)^{2}}},
$$

где $K_{\phi р}$ - расчетный коэффициент фильтрации (по ультразвуку), определяемый по тарировочной связи, согласно измеренной скорости ультразвука, м/с; $K_{\phi p}^{\prime}-$ то же, среднеарифметическая величина; $\kappa_{\phi к}{ }^{-}$коэффициент фильтрации, найденный испытанием стандартных образцов; $K_{\text {фк }}^{\prime}$ - то же, средняя арифметическая величина.

Для связи «скорость ультразвука - коэффициент фильтрации», приведенной на рис. 2 , коэффициент корреляции с учетом (7) равен 0,932 .

Надежность связи $K_{\phi}=f(V)$ необходимо проверить вычислением среднеквадратичного значения отклонений расчетного (по ультразвуку) коэффициента от коэффициента, определенного по испытанию образцов по формуле

$$
\sigma=\sqrt{\frac{\sum\left(\frac{K_{\phi p}-K_{\phi \mathrm{K}}}{K_{\phi p}}\right)^{2}}{n} .}
$$

Результаты статистической обработки значений, полученных в процессе исследования образцов с установленной по коэффициентам фильтрации маркой по водонепроницаемости W8, W10, W12, а также выражения (8) приведены в табл. 2.

\begin{tabular}{|c|c|c|c|c|c|c|}
\hline 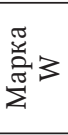 & $\begin{array}{c}\text { Среднее } \\
\text { значение } \\
x\end{array}$ & $\begin{array}{c}\text { Размах } \\
\text { вариации } \\
R\end{array}$ & $\begin{array}{c}\text { Среднее } \\
\text { линейное } \\
\text { отклонение } \\
a \\
\end{array}$ & $\begin{array}{c}\text { Дисперсия } \\
D\end{array}$ & $\begin{array}{l}\text { Стандартное } \\
\text { отклонение } S\end{array}$ & $\begin{array}{c}\text { Средедне- } \\
\text { квадратичное } \\
\text { отклонение, \% }\end{array}$ \\
\hline W8 & 4063,44 & 1456 & 467,259 & 263465,802 & 513,289 & 12,63 \\
\hline W10 & 4726,75 & 984 & 408,75 & 153806,762 & 392,182 & 8,29 \\
\hline W12 & 5124,46 & 814,6 & 327,688 & 124786,035 & 353,250 & 6,89 \\
\hline
\end{tabular}

\section{Результат расчета статистических величин}

Надежность построенной тарировочной связи характеризуется величиной среднего квадратичного отклонения, которое по опыту авторов и других исследователей $[1,6,9]$ должно составлять 8-10\%. Из полученных значений видно, что для марки по водонепроницаемости W8 необходимо корректировать тарировочную зависимость, например, удлинив ряд наблюдений. Новизна предложенного решения реализована в программе определения коэффициента фильтрации бетона на основании результатов ультразвуковой диагностики для ЭВМ, свидетельство № 2016618596.

Заключение. По результатам испытаний контрольных образцов для применения неразрушающего метода определения водонепроницаемости на основе ультразвуковой диагностики необходимо построить графическую зависимость « $K_{\phi}-V »$, которая в дальнейшем будет использоваться при определении марки бетона по водонепроницаемости непосредственно в эксплуатируемых конструкциях.

Тарировочная зависимость для марки бетона по водонепроницаемости W8 требует корректировки, которую можно осуществить, удлинив ряд наблюдений.

Построенные тарировочные зависимости для марок бетона по водонепроницаемости W10 и W12 можно применять для определения водонепроницаемости бетона эксплуатируемых сооружений с использованием предложенного ультразвукового метода, что позволит снизить трудоемкость обследования, особенно на сооружениях большой протяженности.

\section{СПИСОК ЛИТЕРАТУРЫ}

1. Арьков Д.П. Информационные системы в организации и управлении объектами сельскохозяйственного назначения // Интеграционные процессы в науке, образовании и аграрном производстве - залог успешного развития АПК: материалы Междунар. науч.-практ. конф. - Волгоград, 2011. - С. 238-241.

2. Арьков Д.П. Концепция инженерных расчетов с применением информационных технологий // Материалы Междунар. науч.-практ. конф., посвящ. 70-летию Победы в Великой Отечественной войне 19411945 гг. - Волгоград, 2015 г. - Т. 4. - С.468-471.

3. ГОСТ 10180-2012 Бетоны. Методы определения прочности по контрольным образцам - взамен ГОСТ 10180-90; Введ. с 01.07.2003. - М.: Стандартинформ, 2013. -30 c.

4. ГОСТ 12730.5-84 Бетоны. Методы определения водонепроницаемости (с Изменением № 1) - взамен ГОСТ 12730.5-78, ГОСТ 19426-74; Введ. с 1985.07.01. М.: Изд-во Стандартинформ, 2007. - 12 с.

5. Диагностирование состояния грунтовых оснований сооружений мелиоративных систем неразрушающими методами/ С.Я. Семененко [и

Таблица 2 др.] // Стратегические ориентиры инновационного развития АПК в современных экономических условиях: материалы Междунар. науч.-практ. конф. - Волгоград, 2016. - T. 4. - C. 190-196.

6. Семененко О.Г., Попов П.С., Арьков Д.П. Способ комплексной герметизации межпанельных швов и стыков сборных бетонных облицовок мелиоративных кана- 
лов // Междунар. науч.-практ. конф. молодых ученых. Волгоград, 2017. - С. 182-186.

7. Семененко С.Я., Арьков Д.П., Марченко С.С. Метод определения марки бетона по водонепроницаемости на гидротехнических сооружениях / С.Я. Семененко, // Материалы Междунар. науч.-практ. конф., посвящ. 70-летию Победы в Великой Отечественной Войне 1941-1945 гг. - Волгоград, 2015. - Т. 4. - С. 524-528.

8. Семененко С.Я., Арьков Д.П., Марченко С.С. Проверка и практическое внедрение метода диагностики марки по водонепроницаемости бетонных конструкций мелиоративных сооружений // Известия нижневолжского агроуниверситетского комплекса. 2018. -№ 1 (49). - C. 254-261.

9. Sriravindrarajah R., Swamy $R$. Development of a Conductivity Probe to Monitor Setting Time and Moisture Movement in Concrete // Cement, Concrete and Aggregates, Vol. 4, No. 2, 1982, pp. 73-80, ISSN 0149-6123.

10. Relly Victoria Virgil Petrescuetal. Testing by NonDestructive Control // American Journal of Engineering and Applied Sciences 2017, 10 (2):568.583 DOI: $10.3844 /$ ajeassp.2017.568.583.
Семененко Сергей Яковлевич, $\partial-p$ c.- $x$ наук, Федеральный научный иентр агроэкологии, комплексных мелиораций и защитного лесоразведения Российской академии наук. Россия.

Марченко Сергей Сергеевич, канд. техн. наук, Федеральный научный центр агроэкологии, комплексных мелиораций и защитного лесоразведения Российской академии наук. Россия.

Арьков Дмитрий Петрович, канд. техн. наук, Федеральный научный иентр агроэкологии, комплексных мелиораций и защитного лесоразведения Российской академии наук. Россия.

400012, г. Волгоград, ул. Трехгорная, 21.

Тел.: (8442) 54-13-87.

Ключевые слова: ультразвук; диагностика; коэффищиент фильтрации; неразрушающие методы контроля; марка по водонепрониияемости; тарировочная связь.

\title{
THE CALIBRATION RELATIONSHIP BY ULTRASOUND FILTRATION COEFFICIENT OF CONCRETE
}

Semenenko Sergey Yakovlevich, Doctor of Agricultural Sciences, Federal Research Centre of Agroecology, Amelioration and Protective Afforestation RAS. Russia.

Marchenko Sergey Sergeevich, Candidate of Technical Sciences, Federal Research Centre of Agroecology, Amelioration and Protective Afforestation RAS. Russia

Arkov Dmitriy Petrovich, Candidate of Technical Sciences, Federal Research Centre of Agroecology, Amelioration and Protective Afforestation RAS. Russia

Keywords: ultrasound; diagnostics; filtration coefficient; nondestructive testing methods; brand water resistance; calibration communication.
The paper argues the development of new diagnostic methods of filtration coefficient, as one of the important factors affecting the durability of concrete and concrete structures, reclamation and hydraulic engineering structures, knowledge of which contributes to making timely decisions on repair and reconstruction, thereby increasing the service life of buildings, reducing operating costs. The basic methods of control of water-tightness of concrete applied practice are resulted. Describes the main requirements for the samples, the principles of calibration dependences in the control stamps on water resistance of concrete wall operated drainage structures, parameters estimates are based dependencies. ПОДСОЛНЕЧНИКА В КОМБАЙНЕ ПРИ ПОДАЧЕ НА РЕШЕТА ОЧИСТКИ

\author{
СТАРЦЕВ Александр Сергеевич, Саратовский государственный аграрный университет \\ имени Н.И. Вавилова
}

ДЕМИН Евгений Евгеньевич, Саратовский государственный аграрный университет имени Н.И. Вавилова

КУНЬШИн Александр Андреевич, Саратовский государственный аграрный университет имени Н.И. Вавилова

МАВЗОВИН Владимир Святославович, Саратовский государственный аграрный университет имени Н.И. Вавилова

Представлены результаты исследований геометрических параметров сорных примесей вороха подсолнечника, подаваемого на решетные станы очистки со стрясной доски грохота комбайна, обоснована их классификация. Определены геометрические размеры маслосемян сортов «Лакомка», «Саратовский 20» и «Донской». Приведены регулировки жалюзийных и пробивных решет зерноуборочных комбайнов при уборке подсолнечника.

Введение. На агротехнические показатели качества процесса сепарации вороха подсолнечника способны влиять конструкция и регулировки решет, настройка технологических парамет- ров системы очистки комбайна, географические и природные условия уборки, а также геометрические параметры маслосемян различных сортов или видов [2, 4]. 